\title{
MOOC 2050: A FUTURISTIC TOUR
}

\author{
Keith Harman, Oklahoma Baptist University, keith.harman@okbu.edu \\ Alex Koohang, Middle Georgia State College, alex.koohang@maconstate.edu
}

\begin{abstract}
The MOOC (Massively Open Online Course) is attracting significant attention from educators, investors, regulators, and the general public. The proponents of MOOCs suggest that the MOOC is potentially a "gamechanger" or "disruptive technology." We generally agree with that suggestion but offer a caveat: a MOOC like any instructional technology is a tool or an instrument that is value-free till it is "peopled", i.e. any value or utility it has is ultimately bounded by the efficacy with which it is designed and used by educators and students. We therefore present a futuristic vision of the features and functions of an "ideal" or "prototypical" MOOC in order to suggest what value or utility might be gained from a MOOC via its design and application.
\end{abstract}

Keywords: MOOC, future of education, online education, instructional technology and instructional design.

\section{INTRODUCTION}

\section{Rationale, Limitations, and Scope}

MOOCs are a relatively new phenomenon and there exists no definitive history of them. Yet it is safe to argue that they have garnered significant attention since 2010 [4]. A New York Times Online article in 2012 signaled the rise of MOOCs and noted that well over one million students had taken a course via a MOOC and the participation of Stanford University signaled the credibility gained by MOOCs [13]. A recent article in the online version of The Chronicle of Higher Education is indicative of the widespread interest and controversy generated by MOOCs [12].

It is their scale and their open format that make MOOCs a possible learning technology worthy of discussion. We recognize but eschew discussion of issues related to the "branding" and the "commoditization" of higher education. We also eschew consideration of the ownership and the distribution of higher education entities and the courses and the degree programs offered by those entities. Those issues are beyond the scope of this paper. Our focus is upon MOOCs as an instructional technology.

\section{KEY ASSUMPTIONS}

We do not assume that investors or business models will determine the ultimate utility or impacts of MOOCs. We assume that technologists, educational administrators, instructional designers, instructors, and students on both an individual and collective basis will determine the ultimate utility or impacts of MOOCs. We therefore assume it is important to present a futuristic vision of the features and functions of an "ideal" or "prototypical" MOOC in order to suggest what a MOOC could be or should be as regards its design and application.

\section{Format}

A corollary of our first assumption is that a MOOC may be offered in a virtual format, a ground-based format (via a "flipped" format or web-supported format), or a blended format. Our corollary makes no assumption as regards the efficacy of any of the three formats (virtual, ground-based, or blended). We foresee a MOOC that operates on the principle of WYWWYWI ("What You Want When You Want It"). 


\section{Learning Object}

A second corollary of our first assumption is that a MOOC is a learning object. A MOOC (like a discussion board) meets the criteria of a learning object, c.f. [6]. A learning object is " ... not merely a chunk of information packaged to be used in instructional settings. A learning object, therefore, can include anything that has pedagogical value - digital or non-digital such as a case study, a film, a simulation, an audio, a video, an animation, a graphic image, a map, a book, or a discussion board" [6, p. 68].

\section{Information Resources}

Our third assumption is that the content of a MOOC is information resources. Consequently the basis of value of or the underlying value of the content of MOOCs is driven by the "economics of plentitude" versus the "economics of scarcity" [14, p. 48]. By information resources we suggest a "definition" that is in the broadest terms: information that is cognitive in nature (such as a theory) and information that is affective in nature (e.g. emotions induced by posts in a discussion board).

\section{Open Educational Resources}

The forth assumption is that the content of a MOOC is scalable and malleable. MOOC is clearly an extension of Open Educational Resources (OERs). UNESCO [21, par. 3] defined OERs as:

“... technology-enabled, open provision of educational resources for consultation, use and adaptation by a community of users for non-commercial purposes. They are typically made freely available over the Web or the Internet. Their principal use is by teachers and educational institutions to support course development, but they can also be used directly by students. Open Educational Resources include learning objects such as lecture material, references and readings, simulations, experiments and demonstrations, as well as syllabi, curricula and teachers' guides."

Our assumption is based on a premise that a MOOC is an open learning platform [18] although the phrase also denotes "free" access to content.

\section{Customization}

The fifth assumption is that the technology that underlies a MOOC can be leveraged to offer mass customized, digitally-mediated learning [17]. The use of digital technology and the Internet offer well-documented examples of mass customization also referred to as mass personalization [15]. Indeed we would argue that online education already offers mass customization or mass personalization via individual comprehensive or integrative assignments that draw upon students' personal and professional experiences.

\section{Learning Management System (LMS) Platform}

The sixth assumption is that the LMS platform will continue to evolve as technology advances. More efficient technologies will be developed to handle massive traffic of a MOOC taken by a mass of people around the globe. An LMS platform will continue to have interactive learning environment; up to date authoring tools; effective and efficient communication facilities; multimedia and social networking support.

The LMS platform will be flexible, adaptable, and more importantly, it will be fully scalable. The user interface and usability will be a focal point of the LMS platform offering Simplicity, comfort, User-friendliness, Control, Navigability, Recognition, feedback, and direction [11]. 


\section{Pedagogy}

Finally, and most importantly, we assume that the content of a MOOC is experienced by students on an individual and on a collective basis facilitated by or enabled by an instructor; and is therefore subject to constructivist approaches or designs for learning [10]. MOOCs feature individual assignments and assessments and typically employ discussion boards as a way to induce group or collective learning [2]. Constructivism emphasizes collaborative knowledge construction among learners. Jonassen [9] advanced eight principles that are inherent to constructivism. They are:

1. "provide multiple representations of reality;

2. represent the natural complexity of the real world;

3. focus on knowledge construction, not reproduction;

4. present authentic tasks - contextualizing rather than abstracting instruction;

5. provide real-world, case-based learning environments, rather than predetermined instructional sequences;

6. foster reflective practice;

7. enable context-and content dependent knowledge construction; and

8. support collaborative construction of knowledge through social negotiation.” [9, p. 35]

We assume that the element of constructivism regarding active learning in e-learning will be embedded in the design of a MOOC to uphold the quality of instruction [11]. These elements are: "the underpinning elements (real world and relevant examples; exploration; higher-order thinking skills; and scaffolding), the ownership elements (learner's driven goals and objectives; learner's self-mediating and control of learning; learner's self-analysis, self-reflection, self-awareness; learner's own experience; learner's self-assessment; and learner's own representation of ideas and/or concepts), and the engaging elements (learners' active engagement in analysis, evaluation, \& synthesis of multiple perspectives and learners' collaborative assessment)" [11, p. 71].

We assume that the students' role and responsibilities in a MOOC environment will be maintained and encouraged in the process of learning. These roles and responsibilities are "setting their own goals \& objectives, taking control of their own learning; reflecting; being aware of learning; including own experiences; self-assessing; presenting ideas and/or concepts; and actively creating knowledge", which are encouraged and enforced by the instructor [11, p. 71].

We also assume that the instructor's roles and responsibilities in upholding quality of instruction will be sustained in a MOOC environment. These roles and responsibilities are designing pedagogy elements into all "course activities, guide learners to become active learners, and initiate deep learning. furthermore, the instructor is responsible for actively communicating; actively coaching, guiding, mentoring, tutoring, \& facilitating; actively providing feedback; actively assessing; and actively communicating" [11, p. 71].

\section{THE POTENTIAL AND/OR PROMISE OF MOOCS}

The potential and/or promise of MOOCs and the widespread attention they have gained renders them worthy of discussion on their use. We suggest that as a trend in education, MOOCs are at an inflection point, i.e. they are gaining unprecedented attention and momentum. It is opportune; therefore, to suggest how they might evolve or improve. We suggest that a futuristic or visionary perspective allows us to move the discussion towards an ideal or prototype, i.e. what a MOOC could or should do to augment learning.

We realize that there is no universally-accepted definition of the term "MOOC." Likewise there are no universallyaccepted, "construct-level" definitions of terms for "e-learning," "learning object," "flipped course," "hybrid format," or "virtual format." We however assert that the terms are generally understood well enough to be discussed in a "thought piece" or "essay" like this paper as opposed to a field study or full-blown experimental study. 


\section{Issues in Information Systems}

Volume 14, Issue 2, pp.346-352, 2013

\section{VISIONS OF E-LEARNING}

\section{Personalized Content and Personalized Ubiquity}

Personalized learning continues to be a key objective of advocates of e-learning. Andersen [1, p. 16-17] proposes a curated subscription system like an RSS (Rapid Syndication System) devised by a "learning coach" that allows a student to "drink from the information firehose" on a subject or topic. Facer and Sandford [5, p. 83] envision a "personal learning cloud" that includes diverse sources based upon informed choice and standardized provision from a highly atomized, formal educational system. Sims [19] advocates "stakeholder design" of learning that takes into account the learner's culture and learning style. Sims envisions an "active, nomadic learner collaborating with an "absent, responsible teacher" in emergent learning beyond fixed curricula that adapts to multiple intelligences and learning styles [19, p. 160-161]. Tugui [20] posits the use of "calm technologies woven into everyday life" that feature virtual worlds as well as embedded devices in the physical world that "reduce information overload" by permitting users (students) to select what information is at the center of their attention and what information is at the periphery of their attention.

\section{Collaborative}

Futures research has been defined as an attempt to explore relationships between possible, probable, and preferable futures, i.e. what could be, what is likely to be, and what ought to be [5]. As regards collaboration, we envision a MOOC as it should be: a platform for collaboration between student and instructor, between an instructor and multiple students, among students, between a group of instructors and a student, between a group of instructors and a group of students. We concur with Rhoads, Berdan, and Toven-Lindsey [16, p. 109] that MOOCs cannot be constrained by the limits of unidimensional information (course content) delivery. They must include an optimal focus upon social learning as a vehicle for processing information (course content). We envision a MOOC that includes an array of communication platforms and an array of technologies to promote collaborative social learning via asynchronous and synchronous formats. Part of what we envision falls into the realm of "what is likely to be": telepresence, videoconferencing, audioconferencing, blogs, wikis, discussion boards, social media like Facebook, social media like Twitter, recommendation and review engines like Yelp, podcasts, and social bookmarking in texts and in browsers [c.f. 19]. We also envision what could be: virtual worlds [c.f. 20], augmented reality layers [c.f. 19], and robots [8]. We additionally envision a coursepack that incorporates a language translation agent or app that will allow participants to easily communicate with each other. Lastly we envision adaptive features that render a MOOC accessible to those who are challenged by physical impairments.

\section{Offline/Online/No Line: The Infotainment/Edutainment Menu}

We envision a MOOC that can be a complement to or a substitute for ground-based courses rather than only a substitute for them [c.f. 3]. We envision a MOOC that is accessible from any connected device including ebooks, computer tablets, desktop computers, smartphones, and televisions. We also envision a MOOC that identifies instructors and learners who are willing to participate in "meet ups," formal and informal seminars, and tutorials for ground-based learning experiences as well as study tours.

We envision a MOOC that provides access to entertainment products relevant to a course and includes a viewing guide of what is available on a "real time" and on an archived basis. The MOOC 2050 coursepack should also include optional, wearable computing devices and a game or games related to that course or a simulation or virtual world. In sum we envision a MOOCX that is a complement to rather than strictly a substitute for entertainment content like music, videos, movies, books, and games. We envision a MOOC that uses social entertainment platforms such as Spotify, Instagram, and Pinterest to build a sense of community. We lastly envision a MOOC 
whose content is "broadcast ready" and possesses production value equivalent to the production value offered by a media company or news organization.

\section{A MOOC For Any Mood: Course Bots, Silos, Mountains, and Tours}

We envision a MOOC that is modular and thus easily "chunked" into self-contained units of learning that can be experienced on a stand-alone basis or mixed and matched with modules from other MOOCs. The MOOC we envision will be amenable to a student's pace of learning, allowing for an accelerated pace or allowing for learners whose life circumstances make it necessary for them to temporarily "drop out." We lastly envision a MOOC that offers students options as regards membership in a particular learning community or class cohort and the duration of that membership. "Course bots" would allow students to remain engaged but not active.

\section{The Cube: Cafeteria-Style Assessment/Layers Of Learning Matrix: Gradient Grades}

We envision a MOOC that provides students multiple ways to demonstrate their learning. The MOOC we envision will have an assessment plan that is a "meta rubric" that is clearly linked to external valuators. The matrix will essentially be a cube because it will feature the means to assess lower-order to higher-order learning on a scope and on a depth tailored to the needs and pace of the student. All content and activities will be "pre-pathed" or mapped into course objectives and goals. Consequently, we envision a MOOC that offers formal credit as well as informal credit, based upon the request of the student within parameters established by the entity that offers the MOOC or a sponsoring entity.

\section{Forma Summa Laude Maps and Feedback Guides}

The MOOC we envision will include clear and timely formative and summative assessment that maps to curricular objectives and goals. Students will see potential inflection points and the trajectory implied by them. For example, a student will see the likely less than optimal outcome of not mastering a certain skill or concept. Conversely, a student will see the virtuous cycle created by mastering a certain skill or concept. In order for this to work effectively students will have a "feedback guide" and an "instructor of record." The "feedback instructor" will work on mastery of skills and concepts for which the student has yet to reach an acceptable level of proficiency.

\section{Analytics with a Heart and a Brain: The Self-Refreshing Course}

The MOOC we envision will be equipped with application that allow instructors to assess course performance and engagement on an "N of 1" and a " 1 of N" basis. Sentiment analysis will allow instructors to assess student attitudes and opinions on a real time basis just as organizations like I.B.M. (International Business Machines) can monitor social media to assess public opinion and sentiment [7]. We envision a MOOC possessing analytics that will provide instructors the capability to better understand and serve an individual student, a group of students, or all students participating in a MOOC. The MOOC's analytics will inform upcoming learning events (e.g. assignments) so that those upcoming learning events occur using modalities, media, and pacing that are tailored to the characteristics of the student. Lastly, the MOOC will be "self-refreshing" via RSS and automated search bots that would automatically update the course text as new editions appear, edit future and current assignments, and alert MOOC participants to new and to outdated material as well as issues such as "dead" uniform resource locators and copyright restrictions or changes.

\section{CONCLUSIONS}

In this paper, we presented a futuristic vision of the features and functions of an "ideal" or "prototypical" MOOC in order to suggest what value or utility might be gained from a MOOC via its design and application. It is self-evident 


\section{Issues in Information Systems \\ Volume 14, Issue 2, pp.346-352, 2013}

that we envision a MOOC that offers instructional designers and instructors an optimal or at least a feasible or reasonable blend of scale and scope of student engagement, course content, and assessment via e-learning within the format of a MOOC. We therefore essentially envision the MOOC as an "LMS portfolio" as opposed to a "fixed" or "single-purpose-format" LMS. Our vision implies some important questions that bear further discussion:

- How can educators use MOOCs to help address the "digital divide?" Or will MOOCs exacerbate the "digital divide?"

- Even if advances in AI (Artificial Intelligence) make "automated grading" possible, will students accept it as authentic assessment? Will employers? Will accreditors? Will government agencies?

- Even if advances in AI make "automated communication/discussion" possible, will students accept it as authentic? Will this be as good as conducting discussion on a discussion board among a small group of learners to construct knowledge?

- Can a MOOC be learner-centered with massive number of participants "learners"? If so, what appropriate learning principle(s) would be used?

- Will MOOC constitute an appropriate level of "student engagement?" How could student engagement be accomplished soundly with massive number of learners?

- Will MOOC constitute an appropriate level of "instructor accessibility?"

- Should faculty who teach in a MOOC be subject to credentialing standards?

- Should students who participate in a MOOC be required to complete some type of "readiness" or preparatory course prior to participating in a MOOC?

- Should institutions that offer a MOOC be required to submit to program review or focused scrutiny prior to offering a MOOC? Who should conduct that review or focused scrutiny?

We have argued that a MOOC like any instructional technology is a tool or an instrument that is value-free. We stress, that any value or utility of a MOOC is in due course circumscribed by the efficacy with which it is designed and used by educators and students.

\section{REFERENCES}

[1] Andersen, M. H. (2011, January-February). The World is My School: Welcome to the Era of Personalized Learning. The Futurist, 1(45), pp. 12-17.

[2] Boyde, E. (2013, April 15). MOOC Platform to Focus On Group Learning. Retrieved April 19, 2013, from Business School News The Financial Times LTD: http://www.ft.com/cms/s/2/ea8b20e8-a1f0-11e2ad0c-00144feabdc0.html\#axzz2QwA3Gxjv

[3] Doyle, W. (2009, May/June ). Online Education: The Revolution That Wasn't . Change, pp. 56-58.

[4] Dunn, J. (2012, December 24). A Quick Guide To The History Of MOOCs. Retrieved April 19, 2013, from edudemic : http://edudemic.com/2012/12/a-quick-guide-to-the-history-of-moocs/

[5] Facer, K., \& Sandford, R. (2010). The next 25 years?: future scenarios and future directions for education and technology. Journal of Computer Assisted Learning, 74-93.

[6] Harman, K., \& Koohang, A. (2005 ). Discussion Board: A Learning Object . Interdisciplinary Journal of Knowledge and Learning Objects, 1, 67-77 .

[7] IBM. (n.d.). IBM Social Sentiment Index. Retrieved May 1, 2013, from A Smarter Planet: Smarter Analytics: http://www.ibm.com/analytics/us/en/conversations/social-sentiment.html

[8] Jacobs University. (2013, January 8). Robots as teachers: a new addition to the classroom. Retrieved April 29, 2013, from About Jacobs: http://www.jacobs-university.de/2013/01/robots-teachers-newaddition-classroom

[9] Jonassen, D. (1994). Thinking technology. Educational Technology, 34 (4), 34-37.

[10] Knox, J., Boyne, S., Macleod, H., Ross, J., \& Sinclair, C. (2012, August 8). MOOC Pedagogy: The Challenges of Developing for Coursera. Retrieved April 19, 2013, from Association for Learning 


\section{Issues in Information Systems \\ Volume 14, Issue 2, pp.346-352, 2013}

Technology (ALT) Online Newsletter: http://newsletter.alt.ac.uk/2012/08/mooc-pedagogy-the-challengesof-developing-for-coursera/

[11] Koohang, A. (2012). Active learning in e-learning: advancing a systemic model. Issues in Information Systems, 13(1), 68-76.

[12] Kolowich, S. (2013, March 18). Technology: The Minds Behind the MOOCs: The Professors Behind the MOOCs . Retrieved April 19, 2013, from The Chronicle of Higher Educaiton: http://chronicle.com/article/The-Professors-Behind-the-MOOC/137905/\#id=overview

[13] Pappano, L. (2012, November 2). The Year of the MOOC. Retrieved April 19, 2013, from The New York Times Education Life : http://www.nytimes.com/2012/11/04/education/edlife/massive-open-onlinecourses-are-multiplying-at-a-rapid-pace.html

[14] Pearlson, K. E., \& Saunders, C. S. (2010). Managing and Using Informaiton Systems: A Strategic Approach . Hoboken, NJ: John Wiley \& Sons, Inc. .

[15] Piller, F. T., \& Tseng, M. M. (2009). Handbook of Research in Mass Customization and Personalization (Volume 2) . London : World Scientific Publishing Company .

[16] Rhoads, R., Berdan, J., \& Toven-Lindsey, B. (2013). The open courseware movement in higher education: Unmasking power and raising questions about the movement's democratic potential. Educational Theory, 87-109.

[17] Schwann, C., \& McGarvey, B. (2012). Inevitable: Mass Customized Learning: Learning in the Age of Empowerment. Seattle: WA: CreateSpace Independent Publishing Platform: Amazon.com .

[18] Scwartz, J. (2010, September 7). Learnings from a MOOC. Retrieved April 19, 2013, from ETC: Educational Technology and Change : http://etcjournal.com/2010/09/07/learnings-from-a-mooc/

[19] Sims, R. (2008). Rethinking (e)learning: a manifesto for connected generations. Distance Education, 153-164.

[20] Tugui, A. (2011). Calm Technologies: A New Trend for Educational Technologies. World Future Review, 64-72.

[21] UNESCO. (2002). UNESCO promotes new initiative for free educational resources on the Internet. Retrieved May 11, 2013 from http://www.unesco.org/education/news_en/080702_free_edu_ress.shtml

[22] Usluel, Y., \& Mazman, S. (2009). Adoption of Web 2.0 tools in distance education. International Journal of Human Sciences , 89-98. 